Article

\title{
Investigations of AC Microgrid Energy Management Systems Using Distributed Energy Resources and Plug-in Electric Vehicles
}

\author{
Umashankar Subramaniam ${ }^{1, * \mathbb{C}}$, Swaminathan Ganesan ${ }^{2}$, Mahajan Sagar Bhaskar ${ }^{1}(\mathbb{D}$, \\ Sanjeevikumar Padmanaban $\left.{ }^{3}{ }^{(}\right)$, Frede Blaabjerg ${ }^{4}\left(\mathbb{D}\right.$ and Dhafer J. Almakhles ${ }^{1}(\mathbb{C}$ \\ 1 Renewable Energy Lab, Department of Communications and Networks Engineering, College of Engineering, \\ Prince Sultan University (PSU), Riyadh 11586, Saudi Arabia \\ 2 Schneider Electric, Bengaluru 560048, India \\ 3 Department of Energy Technology, Aalborg University, 6700 Esbjerg, Denmark \\ 4 Department of Energy Technology, Aalborg University, 9220 Aalborg, Denmark \\ * Correspondence: shankarums@gmail.com; Tel.: +966-11-4948059
}

Received: 4 April 2019; Accepted: 21 May 2019; Published: 23 July 2019

check for updates

\begin{abstract}
The world has witnessed a rapid transformation in the field of electrical generation, transmission and distribution. We have been constantly developing and upgrading our technology to make the system more economically efficient. Currently, the industry faces an acute shortage of energy resources due to overconsumption by industries worldwide. This has compelled experts to look for alternatives to fossil fuels and other conventional sources of energy to produce energy in a more sustainable manner. The microgrid concept has gained popularity over the years and has become a common sight all over the world because of the ability of a microgrid to provide power to a localized section without being dependent on conventional resources. This paper focuses on development of such an AC hybrid microgrid, which receives power from distributed energy resources (DERs) such as a PV array alongside a battery storage system, and also uses an emergency diesel generator system and an online uninterruptible power supply (UPS) system to provide power to predefined loads under different conditions. This paper also addresses on the power flow to the loads under two main modes of operation-on grid and off grid-and investigates the microgrid in different states and sub-states. The final objective is to design an efficient microgrid model such that it can sustain the multiple loads simultaneously under all operating conditions.
\end{abstract}

Keywords: microgrid; PV inverter; BESS; power flow study; DG

\section{Introduction}

Photovoltaic-based microgrids have gained immense popularity over the past years. They have been hailed as a sustainable and efficient alternative to using fossil fuels and other conventional sources of energy to transmit energy to cities for commercial and domestic use [1-5]. An AC microgrid, alongside the utility grid, would consist of distributed energy resources (DERs). It can consist of a PV array, which could produce power and transmit it to the local loads [6-10]. In addition, it might contain a battery storage system (BSS) that can supply to the loads in case the PV output is not sufficient [11,12]. Emergency diesel generator sets and uninterruptible power supply (UPS) systems can be installed to supply power to the critical loads in an off-grid situation. The power flow in the microgrid is also dependent on the type and number of loads connected to it [13-16]. Different type of loads such as lighting loads and motor loads may be connected to the microgrid that can affect the voltage distribution in several ways $[15,16]$. Energy management schemes for microgrids are discussed in $[17,18]$. The microgrid should be designed in such a way that it can sustain all the necessary loads at 
different stages even in the absence of the main utility grid. The loads, thus, should receive the required voltage supply for their safe and normal operation $[19,20]$. This article is organized as follows, Section 1 presents an introduction to the microgrid concept, and also discusses the proposed microgrid system architecture that is analyzed in the following sections. Section 2 discusses the system specifications used in this analysis for simulation and hardware implementation. Sections 3 and 4 explain different modes of operation of microgrid systems with states and sub-states and the controller response for various operating conditions, and simulation waveforms are presented along with hardware results. Section 5 summarizes the findings as conclusion.

Figure 1 shows a single line diagram representation of the AC microgrid which is designed and studied. The loads mentioned in the diagram have different priority in such a way that the secure loads, are supplied with power under all conditions. The critical loads are also important and supplied accordingly. The sources and loads present in the diagram are discussed in the next section of the paper.

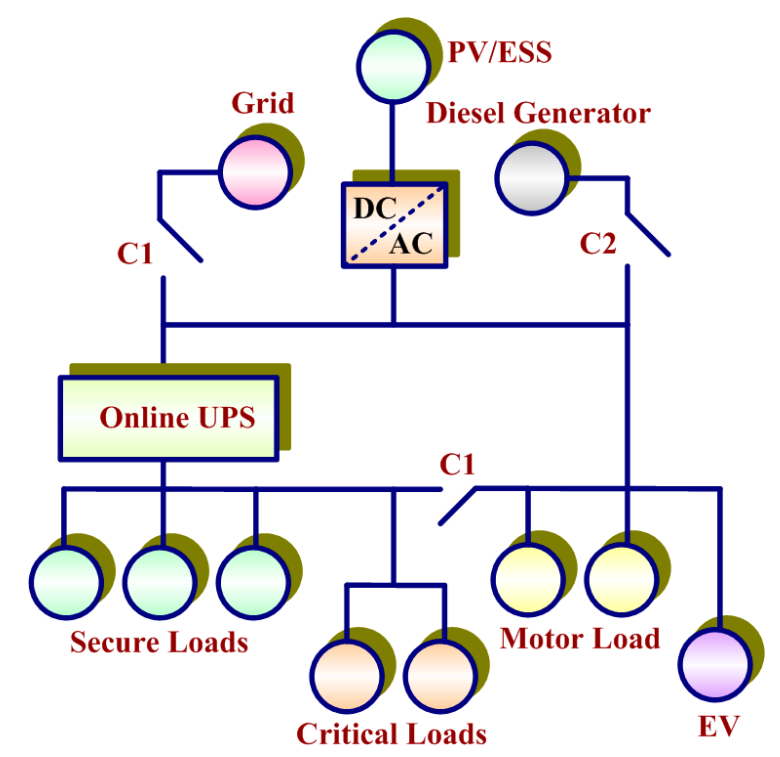

Figure 1. Proposed microgrid architecture under consideration.

\section{System Configuration}

\subsection{Grid}

The utility grid is the main power distribution network that supplies to the consumers in all areas by receiving power from the main generator, where it is generated, and transmitting it over long distances to supply it to the faraway consumers. The grid model taken in this paper is given in Figure 1. This grid with infinite power supplies a single-phase RMS voltage of $230 \mathrm{~V}$ to the microgrid. It is connected to the microgrid through a breaker $\mathrm{C} 1$ which disconnects the grid from the rest of the network in the case of an islanding situation.

\subsection{PV System}

The PV system consists of the PV module which supplies a constant DC voltage of $23.5 \mathrm{~V}$ to the system. This DC voltage is stepped up to a higher voltage value with the help of a boost converter which is then fed to the voltage source inverter which would give an AC output of $230 \mathrm{~V}$ to be fed to the microgrid. The PV module has varying irradiation which can be pre-defined. The parameters of the PV module are explained in [1]. The Simulink model for the PV module is given in Figure 2. The PV module has been developed using its equivalent circuit as a constant current source to estimate current and voltage characteristics for different irradiation and temperature conditions [21]. 


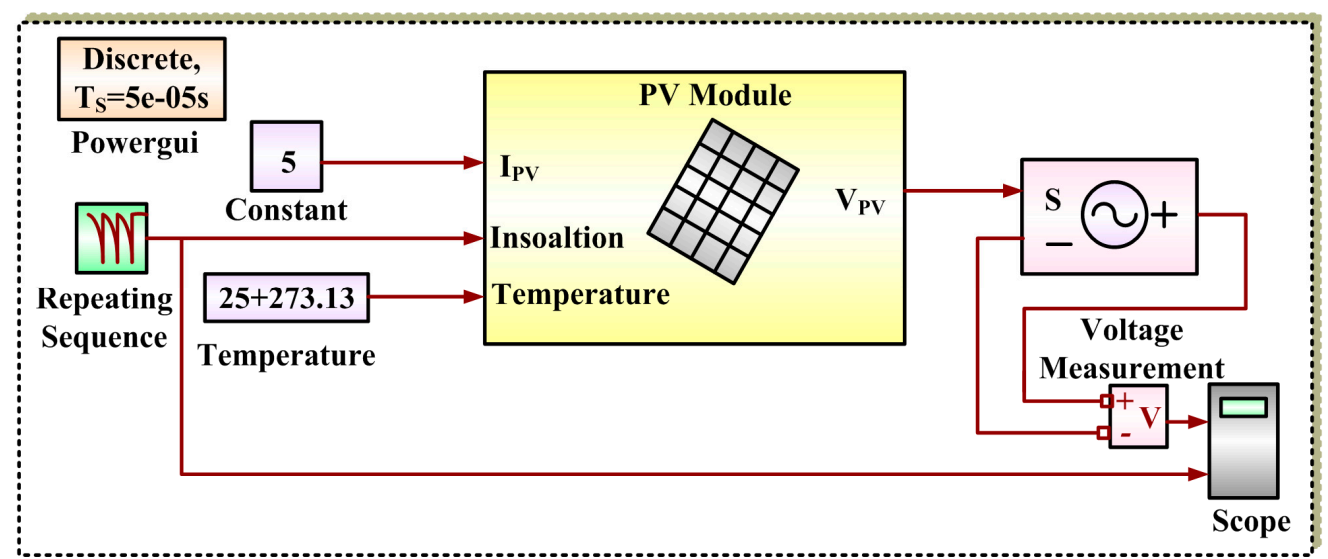

Figure 2. Simulink model of the PV module.

\subsection{Energy Storage System}

The energy storage system is responsible for supporting the microgrid by supplying power when the PV module is not able to support the loads independently. The ESS consists of a battery and the bi-directional converter. The operation of a bi-directional converter to timely charge and discharge the battery has been explained in [2]. The Simulink model for the ESS is given in Figure 3. The ESS is primarily a current source and its Simulink model has been developed using a voltage source inverter (VSI). In this article, we considered the ESS batteries are in fully charged condition, so the input to VSI is directly from a DC source which depicts the battery storage unit of the ESS. The VSI has been operated as a current source by controlling the current using a hysteresis current controller. The reference current for ESS and actual current signals are compared using a suitable comparator and switching pulses for respective phase's solid-state switches in the VSI. The battery parameters are given in Table 1 and are explained in [2].

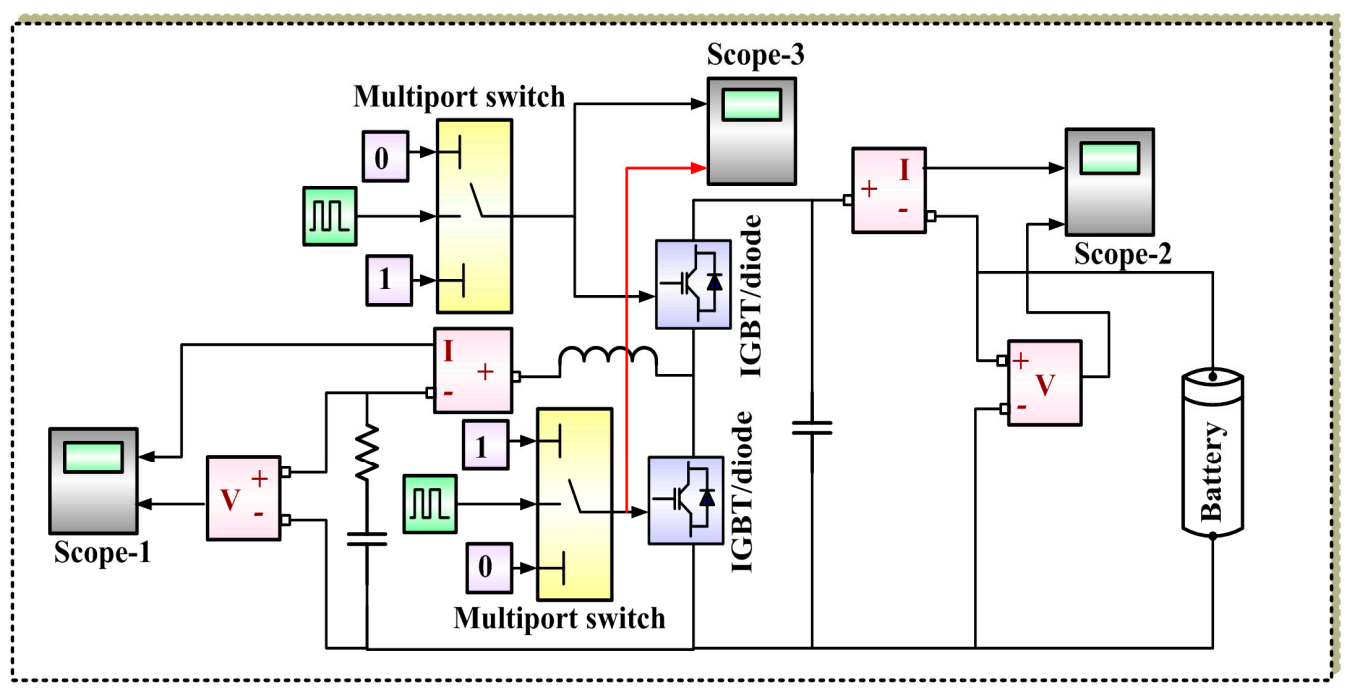

Figure 3. Energy storage system model. 
Table 1. Parameters of the battery in the ESS.

\begin{tabular}{cc}
\hline Parameter & Value \\
\hline Nominal Voltage & $100 \mathrm{~V}$ \\
\hline Rated Capacity & $6.5 \mathrm{Ah}$ \\
\hline Fully Charged Voltage & $108.8816 \mathrm{~V}$ \\
\hline Nominal Discharge Current & $1.3 \mathrm{~A}$ \\
\hline
\end{tabular}

\subsection{Online UPS}

The online UPS is used in the microgrid to play the role of a standby power supply in the network in case of an islanding situation to supply power to the critical loads. The UPS also takes the responsibility of providing the voltage-frequency reference to the network in the absence of the grid.

The UPS is connected to the main line so that it can begin to supply power as soon as the main grid is disconnected from the network. The Simulink model for the UPS model is given in Figure 4. The UPS model consists of a diode rectifier with an active power factor correction circuit, where to maintain a stable dc link voltage, a boost converter has been used and for the inverter stage, a universal block has been considered. LC filters are used at the output. The boost module switching is controlled by the battery state of charge, and battery voltage, while the inverter module switching is done using PWM controller using a standard block.

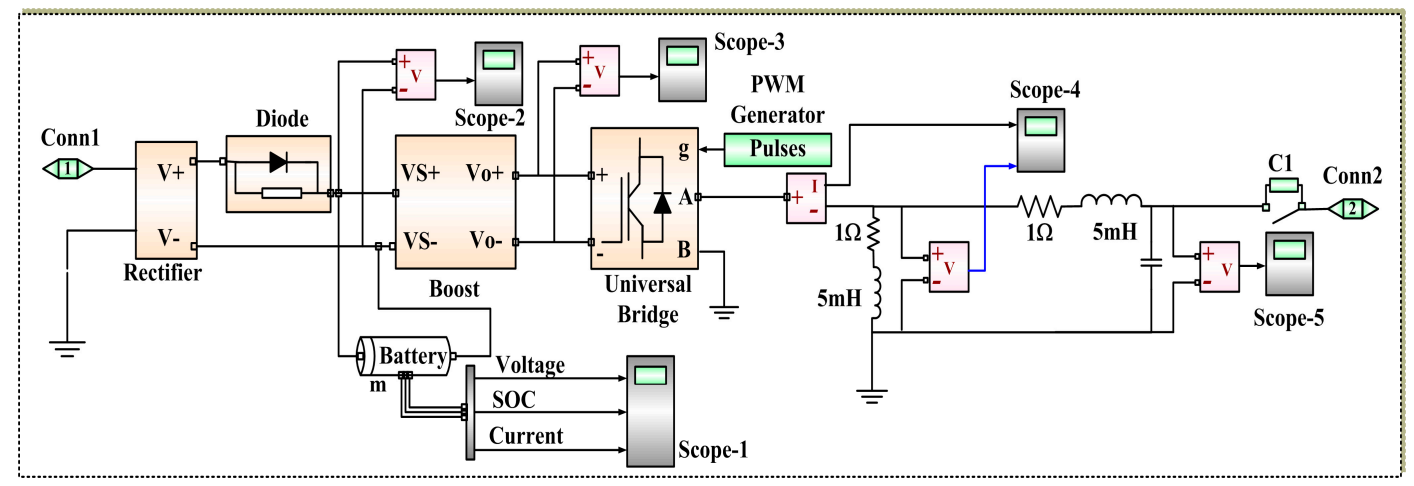

Figure 4. Simulink model of the online UPS.

\subsection{Loads}

The microgrid model includes a few realistic load models which we encounter in everyday commercial usage. Some of these loads include RL lighting loads, single phase motor loads, and three phase EV motor loads. In this paper, we deal with the Simulink models of the below mentioned type of loads and their configuration. The lighting loads are simulated as series RL load and the resistor and inductor power values are pre-defined in the parameters.

The voltage and current values across the load are fed to the power measurement which gives the active and reactive power waveform being supplied to the load. A single phase asynchronous motor has been used as a motor load. The design employs a single phase asynchronous motor of split phase type which is fed with some initial torque to obtain the output. We can measure the rotor speed and electromagnetic torque of the motor at the output end. A three phase electric vehicle (EV) motor load is a realistic load model which takes a single phase voltage input from the microgrid and is converted into a three phase voltage output, which is then fed to a three phase synchronous machine (the EV motor). The model for the same is shown in Figure 5. The parameters of the EV motor are configured such that the three phase machine operates on a three phase voltage supply of $440 \mathrm{~V}$. The single phase to three phase conversion takes place using a three level bridge converter available in MATLAB. 


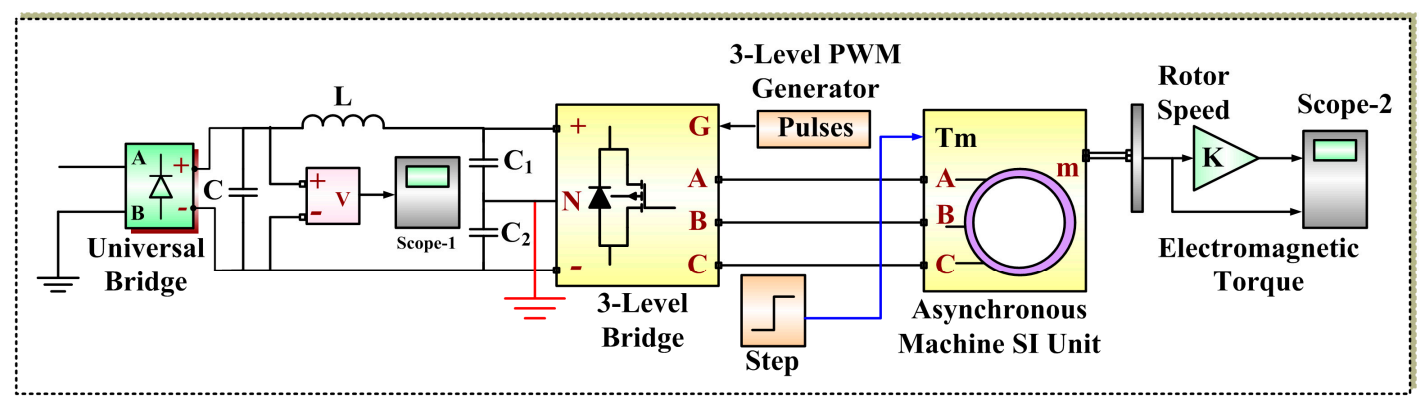

Figure 5. Simulink model of the three phase EV motor.

\section{Principle States: Simulation Results}

The microgrid model obtained after the incorporation of all the above discussed sources and loads is given in Figure 6. The complete system simulation is done using the integration of all sub- systems. The states to be tested for the principle states are discussed in Table 2.

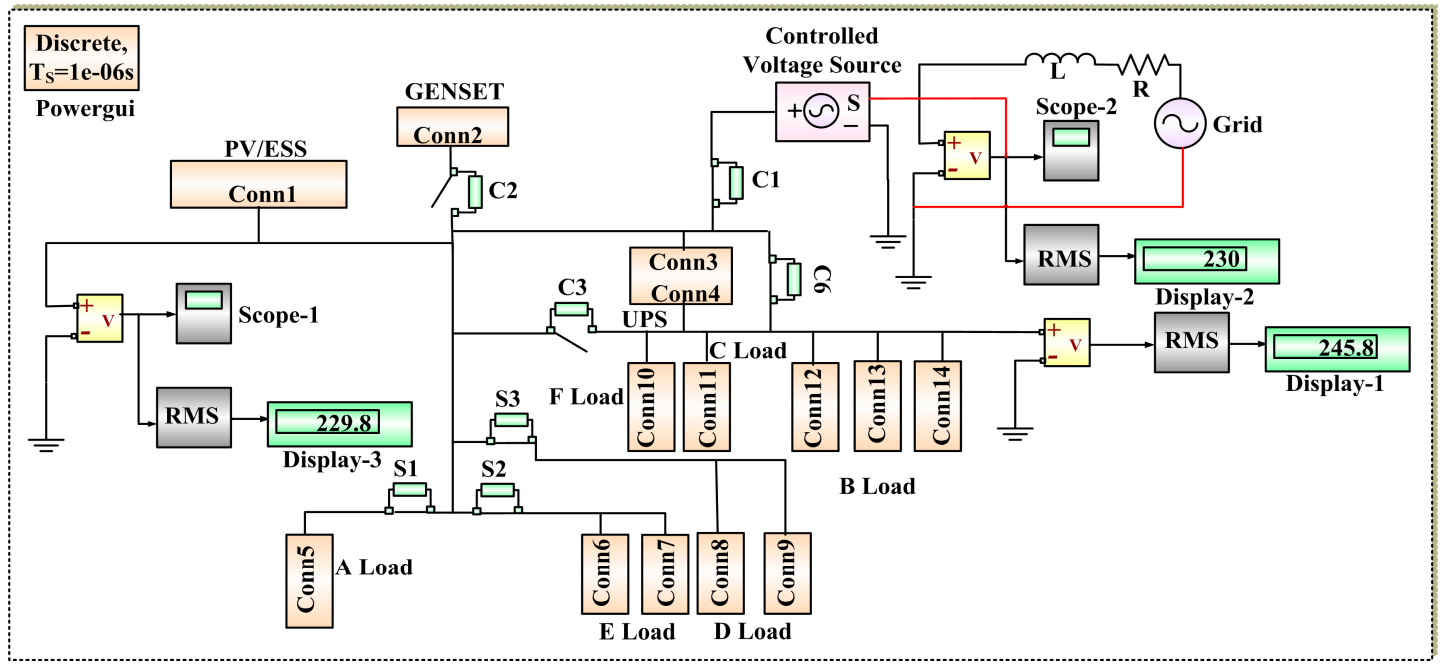

Figure 6. Simulink model of the microgrid system. 
Table 2. Principle states defined in the microgrid system.

\begin{tabular}{|c|c|c|c|c|c|c|c|c|c|c|c|c|c|c|c|c|}
\hline Environment & State Name & Grid & PV & UPS & vs & ESS & $\begin{array}{l}\text { Genset } \\
\text { (DG) }\end{array}$ & $\begin{array}{l}\text { Secure } \\
\text { Loads }\end{array}$ & $\begin{array}{l}\mathrm{D} \\
\text { (Critical) }\end{array}$ & E & A & EV & $\mathrm{C} 1$ & $\mathrm{C} 2$ & $\mathrm{C} 3$ & $\mathrm{C} 4$ \\
\hline \multirow{4}{*}{ ON-GRID } & On-Grid storage & Full & $\begin{array}{l}\text { To } \\
\text { grid/ESS }\end{array}$ & Online & Charging & Charging & Off & Grid & Grid & Grid & Grid & Grid & Close & Open & Open & Close \\
\hline & Auto-consumption & Partial & $\begin{array}{l}\text { To Grid + } \\
\text { Load }\end{array}$ & Online & Off & Supplying & Off & Grid & Grid + ESS & Grid + ESS & Grid + ESS & Grid + ESS & Close & Open & Open & Close \\
\hline & On-Grid Quality & Full & To Load & Online & Supplying & $\begin{array}{l}\text { Supplying/ } \\
\text { Consuming }\end{array}$ & Off & Grid & Grid + ESS & Grid + ESS & Grid + ESS & Grid + ESS & Close & Open & Open & Close \\
\hline & Erasing & Partial & $\begin{array}{l}\text { To Grid + } \\
\text { Load }\end{array}$ & Supplying & Off & Supplying & Off & UPS & ESS & Shed & Shed & No sale & Close & Open & Open & Open \\
\hline \multirow{4}{*}{ OFF-GRID } & Transient-Islaneded & Nil & To Load & Supplying & Off & Off & Off & UPS & Shed & Shed & Shed & Idle & Open & Open & Open & Close \\
\hline & Vital-Islanded & $\mathrm{Nil}$ & $\begin{array}{l}\text { To ESS + } \\
\text { Load }\end{array}$ & Supplying & Supplying & $\begin{array}{l}\text { Charging } \\
\text { from PV }\end{array}$ & Off & UPS & vs & Shed & Shed & Idle & Open & Open & Open & Close \\
\hline & $\begin{array}{l}\text { Power-Islanded } \\
\text { (No DG) }\end{array}$ & Nil & To Load & Supplying & Supplying & Supplying & Off & UPS & ESS & \multicolumn{2}{|c|}{ ESS/Curtailed ESS/Curtailed } & Sell or Buy & Open & Open & Open & Close \\
\hline & $\begin{array}{l}\text { Power-Islanded } \\
\text { (No ESS) }\end{array}$ & Nil & $\begin{array}{l}\text { To ESS + } \\
\text { Load }\end{array}$ & Supplying & Supplying & $\begin{array}{l}\text { Charging } \\
\text { from PV }\end{array}$ & Supplying & UPS & DG & \multicolumn{2}{|c|}{ DG/Curtailed DG/Curtailed } & Sell or Buy & Open & Close & Open & Close \\
\hline $\begin{array}{l}\text { ON-GRID/ } \\
\text { OFF-GRID }\end{array}$ & Isolated & Off & Off & Off & Off & Off & Off & Shed & Shed & Shed & Shed & Idle & Open & Open & Open & Open \\
\hline
\end{tabular}




\subsection{Mode I}

The on-grid storage mode operates from time $t=0$ till $t=0.25 \mathrm{~s}$ simulation time. In this mode, the grid supplies the voltage to all the loads. The PV also supplies to the grid and at the same time, it charges the ESS battery. As a result, the ESS of the battery slowly begins to increase in the beginning. The initial SOC is kept as $50 \%$. The UPS is online but is not supplying to the secure loads as they are receiving the supply from the grid as shown in Figure 7.

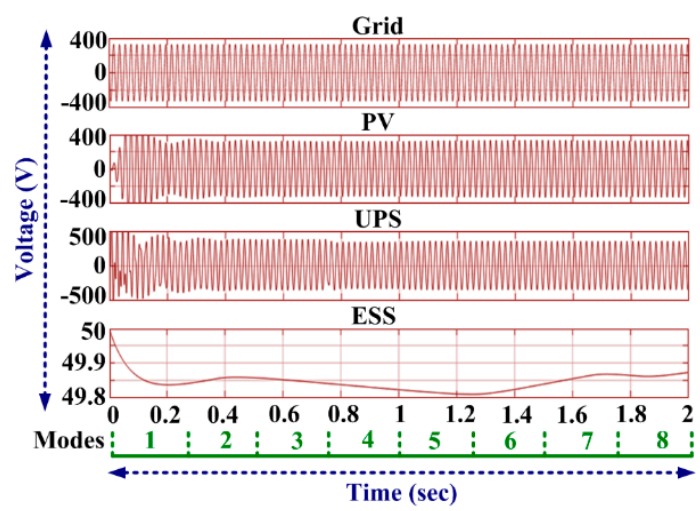

Figure 7. Output voltage of (top to bottom: grid, PV, UPS, and ESS).

\subsection{Mode II}

The auto consumption mode runs from $\mathrm{t}=0.25 \mathrm{~s}$ till $\mathrm{t}=0.50 \mathrm{~s}$ simulation time. In this mode, the PV module irradiation falls below $800 \mathrm{~W} / \mathrm{m}^{2}$, so the ESS begins to supply to the loads alongside the grid. As a result, the SOC of the battery falls. The grid is still supplying to all loads along with the ESS. The voltage supply to the loads is given in Figure 7.

\subsection{Mode III}

The on-grid quality mode runs from $t=0.50 \mathrm{~s}$ to $\mathrm{t}=0.75 \mathrm{~s}$ simulation time. During this mode, the irradiation of the PV module is still below $800 \mathrm{~W} / \mathrm{m}^{2}$, so the ESS continues to supply as its SOC falls further. The PV and the grid collectively supply to all the loads. The UPS remains online as the grid is on. The output voltage and current graph for the loads is shown in Figures 8 and 9, respectively.

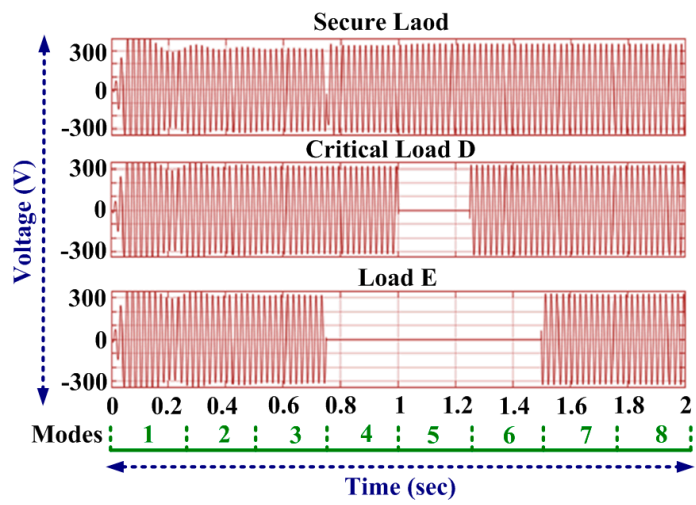

Figure 8. Output voltage of (top to bottom: secure load B, critical load D, and load E. 


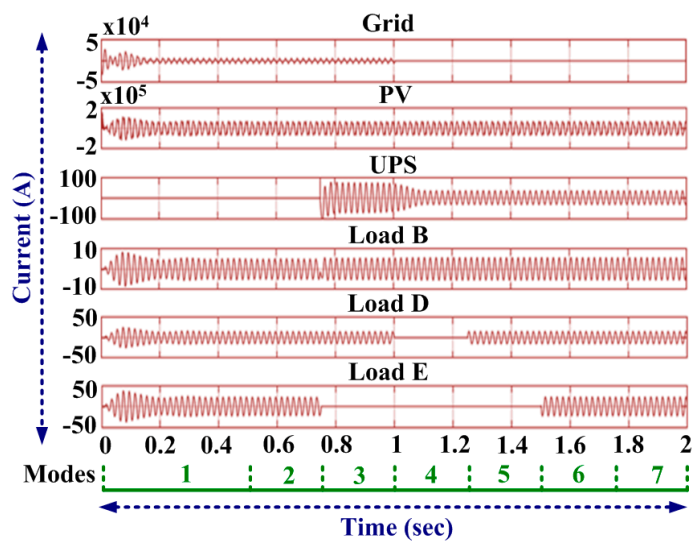

Figure 9. Output current of (top to bottom: grid, PV, UPS, load B, load D, and load E).

\subsection{Mode IV}

The erasing mode runs from $t=0.75 \mathrm{~s}$ to $t=1 \mathrm{~s}$ simulation time. In this mode, the grid provides partial supply to the loads. As a result, the ESS and UPS take up the responsibility to provide power to the secure and critical loads. The UPS supplies to the secure loads and the ESS continues to supply to the critical load. The low priority loads $\mathrm{A}$ and $\mathrm{E}$ are completely shaded in this case. The voltage supply by the UPS to the secure load B is shown in Figure 8.

\subsection{Mode $V$}

The transient islanded mode runs from $t=1 \mathrm{~s}$ to $t=1.25 \mathrm{~s}$ simulation time. In this mode, the system goes off-grid and faces an islanding situation. This mode is activated by default. All the loads and sources except for the secure loads are disconnected from the network. The UPS continues to supply power to the secure loads which is shown in Figure 10 and the output voltage of the loads is shown in Figure 8.

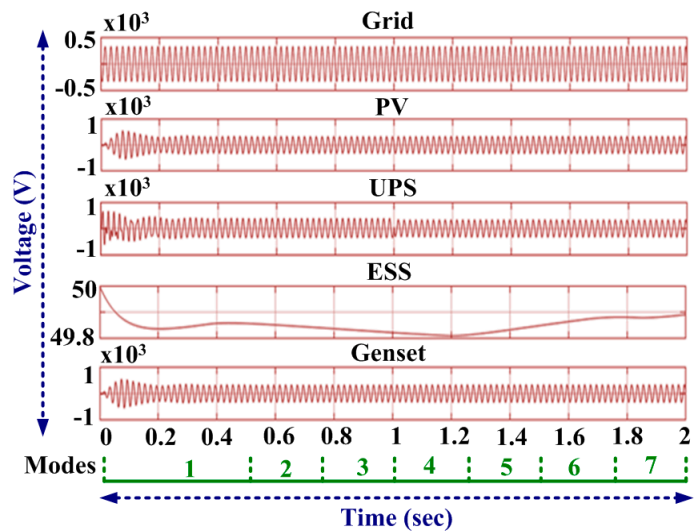

Figure 10. Output voltage of (top to bottom: grid, PV, UPS, ESS, and genset).

\subsection{Mode VI}

The vital islanded mode runs from $t=1.25 \mathrm{~s}$ to $t=1.50 \mathrm{~s}$ simulation time. In this mode, the UPS continues to supply to the secure loads. The PV synchronizes to the grid voltage and takes the responsibility to supply power to the critical loads as shown in Figure 10. The ESS is also charged by the PV as shown in 10. The output current of the loads is shown in Figure 9. 


\subsection{Mode VII}

The power islanded mode runs from $t=1.50 \mathrm{~s}$ to $\mathrm{t}=1.75 \mathrm{~s}$ simulation time. In this mode, the ESS and the UPS both supply to the critical and secure loads, respectively. The output voltage and current of the loads is shown in Figures 11 and 12, respectively. The ESS SOC drops again as shown in Figure 7.

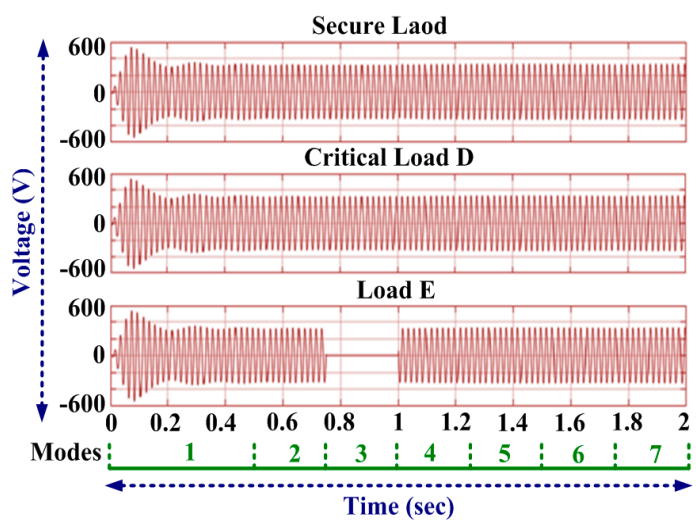

Figure 11. Output voltage of (top to bottom: secure load B, critical load D, and load E).

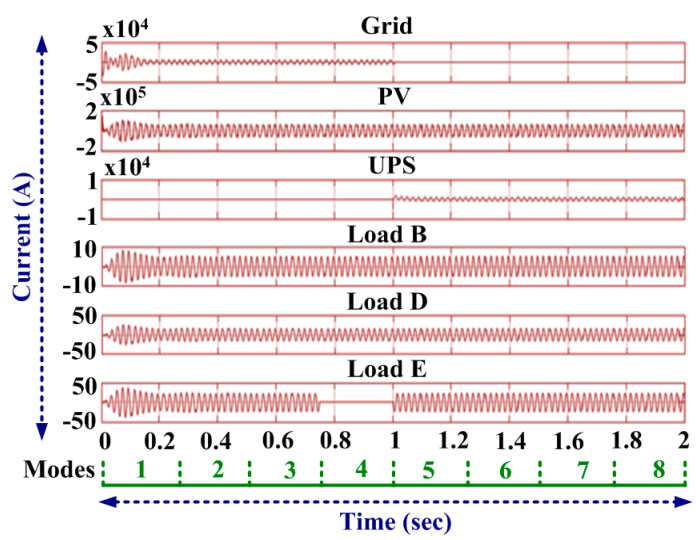

Figure 12. Output current of (top to bottom: grid, PV, UPS, load B, load D, and load E.

\subsection{Mode VIII}

The power islanded mode (No ESS) runs from $t=1.75 \mathrm{~s}$ to $\mathrm{t}=2 \mathrm{~s}$ simulation time. In this mode, the PV module is able to supply to the ESS so it charges as shown in Figure 9. The critical load and the remaining loads are supplied by DG which turns on at $t=1.75 \mathrm{~s}$. The output voltage and current of the loads is shown in Figures 8 and 9, respectively.

\section{Sub-States-Simulation Results}

The states tested for sub-state conditions are given in Table 3. 
Table 3. Sub-states of defined in the microgrid system.

\begin{tabular}{|c|c|c|c|c|c|c|c|c|c|c|c|c|c|c|c|c|}
\hline Environment & State Name & Grid & PV & UPS & vs & ESS & DG & $\begin{array}{l}\text { Secure } \\
\text { Loads }\end{array}$ & $\begin{array}{l}\mathrm{D} \\
\text { (Critical) }\end{array}$ & E & A & EV & $\mathrm{C} 1$ & $\mathrm{C} 2$ & $\mathrm{C} 3$ & $\mathrm{C} 4$ \\
\hline \multirow{3}{*}{ ON-GRID } & $\begin{array}{l}\text { On-Grid Storage } \\
\text { (UPS Fault) }\end{array}$ & Full & $\begin{array}{l}\text { To } \\
\text { grid/ESS }\end{array}$ & Off & Charging & Charging & Off & Grid & Grid & Grid & Grid & Grid & Close & Open & Open & Close \\
\hline & $\begin{array}{l}\text { Auto-consumption } \\
\text { (No ESS) }\end{array}$ & Partial & To Load & Online & Off & Off & Off & Grid & Grid & Grid & Shed & Shed & Close & Open & Open & Close \\
\hline & $\begin{array}{l}\text { On-Grid Quality } \\
\text { (No ESS) }\end{array}$ & Full & $\begin{array}{l}\text { Supplying } \\
\text { to ESS }\end{array}$ & Online & Supplying & $\begin{array}{l}\text { Charging } \\
\text { from PV }\end{array}$ & Off & Grid & Grid & Shed & Shed & Shed & Open & Open & Open & Open \\
\hline \multirow{4}{*}{ OFF-GRID } & $\begin{array}{l}\text { Power-Islanded } \\
\text { (VS SOC Low, } \\
\text { ESS On) }\end{array}$ & Nil & $\begin{array}{l}\text { Supplying } \\
\text { to VS }\end{array}$ & $\begin{array}{l}\text { Supplying and } \\
\text { V-f reference } \\
\text { to ESS }\end{array}$ & $\begin{array}{l}\text { Charging } \\
\text { from PV }\end{array}$ & Supplying & Off & UPS & ESS & ESS & Shed & Shed & Open & Open & $\begin{array}{l}\text { Close for V-f } \\
\text { reference } \\
\text { from UPS }\end{array}$ & Close \\
\hline & $\begin{array}{l}\text { Power-Islanded } \\
\text { (VS fault, } \\
\text { ESS On) }\end{array}$ & Nil & $\begin{array}{l}\text { Supplying } \\
\text { to Load }\end{array}$ & $\begin{array}{l}\text { Supplying and } \\
\text { V-f reference } \\
\text { to ESS }\end{array}$ & Off & Supplying & Off & UPS & ESS & ESS & Shed & Shed & Open & Open & $\begin{array}{l}\text { Close for V-f } \\
\text { reference } \\
\text { from UPS }\end{array}$ & Close \\
\hline & $\begin{array}{l}\text { Power-Islanded } \\
\text { (VS SOC Low, } \\
\text { DG On) }\end{array}$ & Nil & To VS & $\begin{array}{l}\text { Supplying and } \\
\text { V-f reference } \\
\text { to DG }\end{array}$ & $\begin{array}{l}\text { Charging } \\
\text { from PV }\end{array}$ & Off & On & UPS & DG & DG & Shed & Shed & Open & Close & $\begin{array}{l}\text { Close for V-f } \\
\text { reference } \\
\text { from UPS }\end{array}$ & Close \\
\hline & $\begin{array}{l}\text { Power-Islanded } \\
\text { (VS fault, } \\
\text { DG On) }\end{array}$ & Nil & $\begin{array}{l}\text { Supplying } \\
\text { to ESS }\end{array}$ & $\begin{array}{l}\text { Supplying and } \\
\text { V-f reference } \\
\text { to DG }\end{array}$ & Off & $\begin{array}{l}\text { Charging } \\
\text { from PV }\end{array}$ & On & UPS & DG & DG & $\begin{array}{l}\text { Completely } \\
\text { Shedded }\end{array}$ & $\begin{array}{l}\text { Completely } \\
\text { Shedded }\end{array}$ & Open & Close & $\begin{array}{l}\text { Close for V-f } \\
\text { reference } \\
\text { from UPS }\end{array}$ & Close \\
\hline
\end{tabular}




\subsection{Mode I}

The on-grid storage mode (UPS fault) operates from time $t=0$ till $t=0.50 \mathrm{~s}$ simulation time. In this mode, the grid independently supplies power to all the loads without any external source. The PV also supplies to the grid and at the same time, it charges the ESS battery. As a result, the ESS of the battery slowly begins to increase in the beginning. The initial SOC is kept as 50\%. The UPS is off and is not supplying to the load or charging at this point. The output voltage and current of loads is shown in Figures 11 and 12, respectively.

\subsection{Mode II}

The auto consumption mode (no ESS) runs from $\mathrm{t}=0.50 \mathrm{~s}$ till $\mathrm{t}=0.75 \mathrm{~s}$ simulation time. In this mode, the PV module supplies only to the load and the ESS is disconnected from the network as shown in Figure 10. The UPS is not supplying power. The grid is still supplying independently to all loads and the loads A and EV are disconnected from the network as shown in Figure 11.

\subsection{Mode III}

The power islanded mode (Vs SOC low, ESS on) runs from $t=1.00 \mathrm{~s}$ to $t=1.25 \mathrm{~s}$ simulation time. In this mode, the UPS begins to supply to the secure loads as the system enters off grid mode. The switch C3 turns on as UPS also provides the V-f reference to the ESS. The ESS starts supplying the critical load and load E as its SOC falls as is shown in Figure 12. The output voltage and current of secure load B due to the UPS is shown in Figures 11 and 12, respectively.

\subsection{Mode IV}

The power islanded mode (Vs fault, ESS on) runs from $t=1.25 \mathrm{~s}$ to $t=1.50 \mathrm{~s}$ simulation time. In this mode, the system goes off-grid and faces islanding situation. This mode is activated by default. All the loads and sources except for the secure loads are disconnected from the network. The UPS continues to supply to the secure loads which is shown in Figure 11.

\subsection{Mode V}

The power islanded mode (Vs SOC low, DG on) runs from $t=1.50 \mathrm{~s}$ to $t=1.75 \mathrm{~s}$ simulation time. In this mode, the UPS continues to supply to the secure loads and provides V-f reference to the DG. The ESS turns off and the DG takes the responsibility to supply power to the critical loads.

The PV synchronizes to the grid voltage and takes the responsibility to supply to the critical loads as shown in Figure 11. The ESS is also charged by the PV as shown in Figure 10.

\subsection{Mode VI}

The power islanded mode (Vs fault DG on) runs from $t=1.75 \mathrm{~s}$ to $t=2.00 \mathrm{~s}$ simulation time. In this mode, the UPS continues to supply to secure loads as shown in Figure 12. The DG supplies to the critical and load E. The loads A and EV continue to remain disconnected as shown in Figure 11. The ESS is connected to the supply again and charged by the PV as shown in Figure 10.

Figure 13 depicts the hardware set up of the microgrid under consideration. The experimental setup was developed with grid tied solar inverter of $25 \mathrm{~kW}$ size, energy storage system of $10 \mathrm{~kW}$ size, uninterrupted power supply of $8 \mathrm{~kW}$ size and suitable digital signal processors, circuit breakers, programmable logic controllers and communication protocol converters for serial to TCP/IP conversion along with loads. 


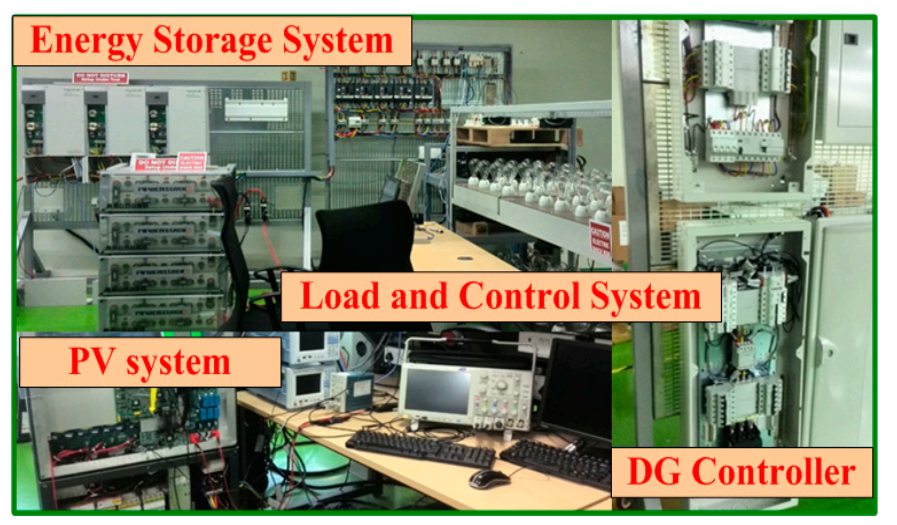

Figure 13. Experimental setup of the microgrid under consideration.

In addition to the above devices, for performing system configuration a human machine interface has been used. The above discussed energy management scheme has been developed in a programmable logic controller, and the controller sends command to the various sources and loads based on the pre-defined operating scenario. The local embedded controller in respective device receives the command and performs necessary control actions. The developed microgrid system has been tested for various operating conditions from grid connected mode to islanded mode of operation. The system operation stability is achieved through fine tuning of controllers. The simulation results are verified and compared with experimental set up for performance as well as response time.

Figure 14 presents the response from experimental set up for sudden reduction in frequency to below threshold limit under islanded mode of operation. The results confirm the controller is able to activate the command to disconnect the system quickly to ensure no damage to sources and loads. The waveform shows there is a low frequency event occurs at instant ' $a$ ' and immediately the controller sends command to disconnect the sources and loads, less than $130 \mathrm{~ms}$ the disconnection happens at instant ' $b$ ', the same can be observed in the oscilloscope view in the Figure 14.

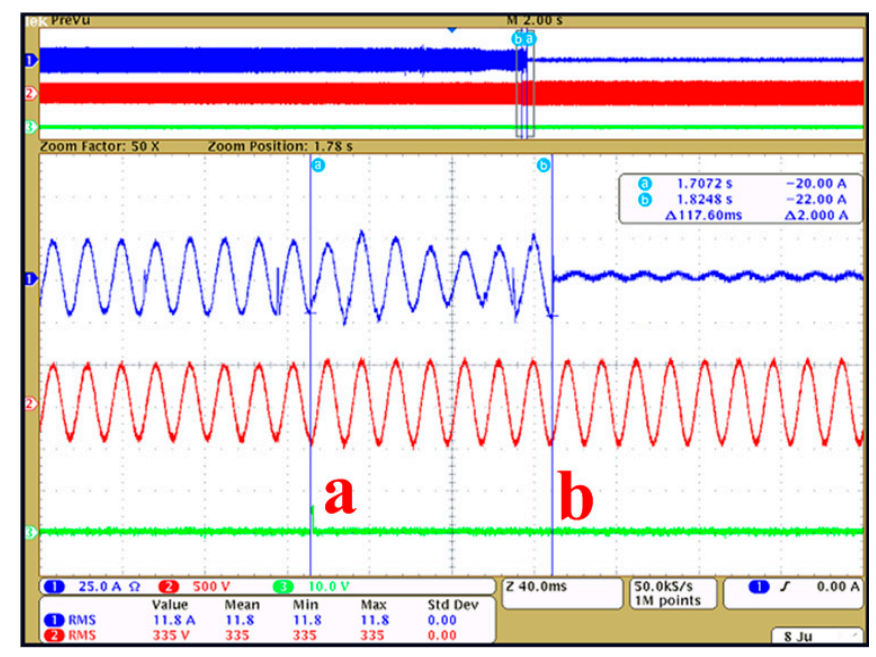

Figure 14. Microgrid system response in islanded more of operation for sudden low frequency operating condition.

\section{Conclusions}

Microgrids form an essential part of our plans for sustainable development. Through this paper, an attempt has been made to demonstrate the ability of such grid networks to provide adequate power to multiple loads. Such a concept would not only provide clean energy to the targeted consumers, but would also make the community independent of external sources of energy. Naturally, such a 
concept has its own drawbacks which need to be analyzed but it can become a large scale phenomenon. The power quality issues such as harmonics and the high initial costs of such a Microgrid cause the main hindrance in its further development. These issues need to be addressed immediately and suitable solutions need to be devised before we can implement a practical model for the same. Needless to say, the future of clean energy lies in its utilization by the consumers. Such AC/DC microgrid ideas need to be researched and developed further to achieve the ideal state of global sustainability. From the analysis it is evident that the proposed system level architecture can be apt for remote locations where the utility grid is unreliable or not present, thus saving huge capital investments from a utility infrastructure perspective. By having more renewable energy penetration, the operating cost of the system can be very minimal.

Author Contributions: All authors contributed equally for the final decimation of the research article in its current form.

Funding: No source funding available for this research work.

Acknowledgments: The authors like to express their sincere gratitude to the Renewable Energy Lab, College of Engineering, Prince Sultan University, Riyadh 11586, Saudi Arabia for giving opportunity to execute the project in this area.

Conflicts of Interest: The authors declare no conflict of interest.

\section{References}

1. Vavilapalli, S.; Padmanaban, S.; Subramaniam, U.; Mihet-Popa, L. Power Balancing Control for Grid Energy Storage System in Photovoltaic Applications-Real Time Digital Simulation Implementation. Energies 2017, 10, 928. [CrossRef]

2. Kanchev, H.; Lu, D.; Colas, F.; Lazarov, V.; Francois, B. Energy Management and Operational Planning of a Microgrid with a PV-Based Active Generator for Smart Grid Applications. IEEE Trans. Ind. Electron. 2011, 58, 4583-4592. [CrossRef]

3. Ganesan, S.; Padmanaban, S.; Varadarajan, R.; Subramaniam, U.; Mihet-Popa, L. Study and Analysis of an Intelligent Microgrid Energy Management Solution with Distributed Energy Sources. Energies 2017, 10, 1419. [CrossRef]

4. Chen, C.; Duan, S.; Cai, T.; Liu, B.; Hu, G. Smart energy management system for optimal microgrid economic operation. IET Renew. Power Gener. 2011, 5, 258-267. [CrossRef]

5. Bhaskar, M.S.; Meraj, M.; Iqbal, A.; Padmanaban, S.; Maroti, P.K.; Alammari, R. High Gain Transformer-Less Double-Duty-Triple-Mode DC/DC Converter for DC Microgrid. IEEE Access 2019, 7, 36353-36370. [CrossRef]

6. Ganesan, S.; Ramesh, V.; Umashankar, S.; Sanjeevikumar, P. Fuzzy-Based Microgrid Energy Management System Using Interleaved Boost Converter and Three-Level NPC Inverter with Improved Grid Voltage Quality. In Advances in Smart Grid and Renewable Energy; Lecture Notes in Electrical Engineering Book Series; Springer: Singapore, 2018; Volume 435, pp. 325-337.

7. Gaurav, S.; Birla, C.; Lamba, A.; Umashankar, S.; Ganesan, S. Energy Management of PV—Battery Based Microgrid System. Procedia Technol. 2015, 21, 103-111. [CrossRef]

8. Chandramohan, K.; Padmanaban, S.; Kalyanasundaram, R.; Bhaskar, M.S.; Mihet-Popa, L. Grid Synchronization of a Seven-Phase Wind Electric Generator Using d-q PLL. Energies 2017, 10, 926. [CrossRef]

9. Singh, S.; Singh, M.; Kaushik, S.C. Optimal power scheduling of renewable energy systems in microgrids using distributed energy storage system. IET Renew. Power Gener. 2016, 10, 1328-1339. [CrossRef]

10. Lin, R.; Yang, M.; Li, H. Analysis of Parallel Photovoltaic Inverters with Improved Droop Control Method. In Proceedings of the 2015 International Conference on Modeling, Simulation and Applied Mathematics, Phuket, Thailand, 23-24 August 2015.

11. Adhikari, S.; Li, F. Coordinated V-f and P-Q Control of Solar Photovoltaic Generators with MPPT and Battery Storage in Microgrids. IEEE Trans. Smart Grid 2014, 5, 1270-1281. [CrossRef]

12. Hosseinzadeh, M.; Salmasi, F.R. Power management of an isolated hybrid AC/DC micro-grid with fuzzy control of battery banks. IET Renew. Power Gener. 2015, 9, 484-493. [CrossRef] 
13. Kim, S.; Jeon, J.; Cho, C.; Ahn, J.; Kwon, S. Dynamic Modeling and Control of a Grid-Connected Hybrid Generation System With Versatile Power Transfer. IEEE Trans. Ind. Electron. 2008, 55, 1677-1688. [CrossRef]

14. Pota, H.R.; Hossain, M.J.; Mahmud, M.A.; Gadh, R. Control for microgrids with inverter connected renewable energy resources. In Proceedings of the 2014 IEEE PES General Meeting | Conference \& Exposition, National Harbor, MD, USA, 27-31 July 2014; pp. 1-5.

15. Hossain, E.; Perez, R.; Padmanaban, S.; Siano, P. Investigation on the Development of a Sliding Mode Controller for Constant Power Loads in Microgrids. Energies 2017, 10, 1086. [CrossRef]

16. L-Nussairi, M.K.A.; Bayindir, R.; Padmanaban, S.; Mihet-Popa, L.; Siano, P. Constant Power Loads (CPL) with Microgrids: Problem Definition, Stability Analysis and Compensation Techniques. Energies 2017, 10, 1656. [CrossRef]

17. Yang, H.-T.; Liao, J.-T. Hierarchical energy management mechanisms for an electricity market with microgrids. IET J. Eng. 2014, 2014, 477-486. [CrossRef]

18. Guo, Z.; Sha, D.; Liao, X. Energy management by using point of common coupling frequency as an agent for islanded microgrids. IET Power Electron. 2014, 7, 2111-2122. [CrossRef]

19. Kouro, S.; Malinowski, M.; Gopakumar, K.; Pou, J.; Franquelo, L.G.; Wu, B.; Rodriguez, J.; Perez, M.; Leon, J. Recent Advances and Industrial Applications of Multilevel Converters. IEEE Trans. Ind. Electron. 2010, 57, 2553-2580. [CrossRef]

20. Padmanaban, S.; Grandi, G.; Blaabjerg, F.; Wheeler, P.; Siano, P.; Hammami, M. A Comprehensive Analysis and Hardware Implementation of Control Strategies for High Output Voltage DC-DC Boost Power Converter. Int. J. Comput. Intell. Syst. 2017, 10, 140-152. [CrossRef]

21. Ganesan, S.; Ramesh, V. Performance Improvement of Micro Grid Energy Management System using Interleaved Boost Converter and P\&O MPPT Technique. Int. J. Renew. Energy Res. 2016, 6, 663-671.

(C) 2019 by the authors. Licensee MDPI, Basel, Switzerland. This article is an open access article distributed under the terms and conditions of the Creative Commons Attribution (CC BY) license (http://creativecommons.org/licenses/by/4.0/). 